\title{
Mast cell activation is differentially affected by heat shock
}

\author{
Esmaeil Mortaz ${ }^{\mathrm{a}}$, Frank A. Redegeld ${ }^{\mathrm{a}}$, \\ Maurice W. van der Heijden ${ }^{\mathrm{a}}$, Hector R. Wong ${ }^{\mathrm{b}}$, Frans P. Nijkamp ${ }^{\mathrm{a}}$, and Ferdi Engels ${ }^{\mathrm{a}}$ \\ ${ }^{a}$ Department of Pharmacology and Pathophysiology, Utrecht Institute for \\ Pharmaceutical Sciences, Utrecht University, Utrecht, The Netherlands; ${ }^{\mathrm{b}}$ Division of Critical \\ Care Medicine, Children's Hospital Medical Center and Children's Hospital Research Foundation, Cincinnati, Ohio, USA
}

(Received 15 March 2005; revised 13 April 2005; accepted 4 May 2005)

\begin{abstract}
Objective. Mast cells play pivotal roles in immediate-type and inflammatory allergic and nonallergic reactions. Cross-linking of the high-affinity receptor for IgE (FceRI) on mast cells activates a signaling pathway leading to $\mathrm{Ca}^{2+}$ mobilization and is followed by degranulation and the release of histamine and other preformed mediators, as well as de novo synthesis of arachidonic acid metabolites. In a previous study, we have demonstrated that heat shock activates heat shock transcription factor-1 (HSF-1), induces heat shock protein 70 (HSP70), and suppresses cytokine production in bone marrow-derived mast cells (BMMC). In this study, we further investigated the effects of heat shock on the activation of mast cells and the release of mast cell mediators.

Methods. In mouse mast cells, derived from a culture of bone marrow cells of male BALB/ cBy and null HSF-1 ${ }^{-1-}$ mice, responsiveness to heat shock was monitored by measuring $\beta$ hexosaminidase and leukotriene $\mathrm{C}_{4}\left(\mathrm{LTC}_{4}\right)$ release.

Results. Using BMMC, we found that heat shock inhibits degranulation of BMMC without affecting leukotriene production. To further elucidate the mechanism of suppression of degranulation, we studied the effects of heat shock on the regulation of signal transduction in more detail. We found that heat shock inhibits calcium mobilization and tyrosine phosphorylation of Syk and SHIP upon IgE receptor activation, but increases the phosphorylation of SHP-1 and -2. Moreover, our results revealed that suppression of tyrosine phosphorylation of Syk and SHIP coincided with an increased tyrosine phosphatase activity.

Conclusion. The inhibitory action of heat shock toward mast cell degranulation is likely due to shifting the balance between kinase and phosphatase activity. (C) 2005 International Society for Experimental Hematology. Published by Elsevier Inc.
\end{abstract}

\section{Introduction}

Mast cells are critical effector cells of allergic inflammation, releasing mediators that are preformed or newly synthesized in response to diverse stimuli including stem cell factor (SCF) and immunoglobulin (Ig) E-mediated activation [1]. The signaling pathway leading to degranulation of mast cells after engagement of the FceRI receptor by antigen and antibody has been extensively characterized [2-4]. Engagement of the receptor leads to activation of tyrosine kinases,

Offprint requests to: Ferdi Engels, Ph.D., Department of Pharmacology and Pathophysiology, Utrecht Institute for Pharmaceutical Sciences, Utrecht University, P.O. Box 80082, 3508 TB Utrecht, The Netherlands; E-mail: G.M.H.Engels@pharm.uu.nl activation of phospholipase C (PLC), an increase in diacylglycerol, and mobilization of $\mathrm{Ca}^{2+}$ from internal stores by inositol triphosphate. This is followed by activation of protein kinase $\mathrm{C}$ (PKC) accompanied by an increase in mitogenactivated protein kinase activity (MAPK) and a $\mathrm{Ca}^{2+}$ influx from external sources. The increase in intracellular $\mathrm{Ca}^{2+}$ is required for the release of preformed mediators from mast cell granules [3,5]. In addition, eicosanoids [4] and various cytokines can be released independently of these degranulation events. The cysteinyl leukotrienes (cys-LTs), LTC ${ }_{4}$, $\mathrm{LTD}_{4}$, and $\mathrm{LTE}_{4}$, are generated mainly by mast cells and eosinophils and are able to contract airway smooth muscle and increase mucus secretion and vascular permeability and recruit eosinophils. 
Protein tyrosine phosphorylation is an early and critical event in FceRI-mediated signal transduction in basophils and mast cells [6]. After receptor aggregation, there is phosphorylation of the tyrosine residues in immunoreceptor tyrosine-based activation motifs (ITAMs) of the $\beta$ - and $\gamma$ chains, which then recruit the spleen tyrosine kinase (Syk)/ ZAP-70 family protein tyrosine kinases (PTK) and propagate downstream signals $[7,8]$. The phosphorylation of these downstream molecules then results in cell activation. The balance between the action of protein tyrosine phosphatases (PTPs) and kinases regulates the extent of tyrosine phosphorylation and therefore the signal transduction that results in degranulation and the release of inflammatory mediators.

Protein tyrosine phosphatases SHP-1 (SH2 domaincontaining protein tyrosine phosphatase 1) and SHP-2 (SH2 domain-containing protein tyrosine phosphatase 2) have two SH2 domains and their substrates are tyrosyl-phosphorylated proteins [9]. SHP-1 is thought to dephosphorylate tyrosines in ITAMs [10] protein tyrosine kinases and/or adapter proteins such as SLP-76 [11] whose phosphorylation is critical for activation signals. SHP-1 thus stops the initial steps of signal transduction of mast cells.

Another regulatory protein in mast cell degranulation is SH2-bearing inositol phosphate phosphatase (SHIP) [12]. SHIP has been shown to inhibit immune receptor activation by binding to the tyrosine-phosphorylated ITIM of the inhibitory co-receptor FcRIIB and inhibiting FceRI- and B-cell receptor-induced calcium influx, respectively [13].

In recent years, accumulating evidence suggests that the heat shock (stress) response confers a protective effect against a variety of harmful factors, including hyperthermia, oxidants, and inflammation [14,15]. Although the exact mechanisms by which the stress response exerts its protective effect are not completely understood, it is generally believed that heat shock proteins act as "chaperones" for damaged proteins and prevent aggregation of these proteins, thus preventing further cell injury [16]. One of the most widely studied inducible heat shock proteins is heat shock protein 70 (HSP70), the induction of which is commonly used to monitor the heat shock response. The expression of HSPs is governed by heat shock factors (HSFs) acting as transcription factors [16]. The observations that HSF-1 can directly repress activation of the pro-interleukin- $1 \beta$ promoter [17] and that specific overexpression of HSP70 inhibits astroglial expression of inducible nitric oxide synthase [18] suggest that these two components of heat shock response mediate repression of cellular proinflammatory responses.

We previously found that heat shock induced HSF-1 activation and HSP70 expression in bone marrow-derived mast cells (BMMC) (manuscript submitted). However, many issues remain unresolved with respect to interaction with immediate hypersensitivity reactions [19]. Therefore, the objective of this study was to investigate the mechanisms by which the heat shock/stress response modulates mast cell degranulation and leukotriene synthesis.

\section{Materials and methods}

\section{Reagents and cytokines}

Competition Enzyme Immunoassay kit (EIA) for measurement of LTC $_{4}$ was obtained from Amersham (Amersham Pharmacia Biotech, Roosendaal, The Netherlands). Fura Red, AM and Fluo-3 AM for calcium measurements by flow cytometry methods (fluorescence-activated cell sorting [FACS]) were purchased from Molecular Probes (Leiden, The Netherlands) and 2,4-dinitrophenyl human serum albumin (DNP-HSA) was purchased from Sigma (Sigma-Aldrich, Zwijndrecht, The Netherlands). Recombinant mouse interleukin (IL)-3 and SCF (stem cell factor) cytokines were obtained from PeproTech (Sanbio, Uden, The Netherlands). Rabbit polyclonal anti-Syk, mouse monoclonal anti-SH-PTP1 (sc-7289) and SH-PTP2 (sc-7384), and rabbit polyclonal anti-SHIP antibodies were obtained from Santa Cruz (Tebu-bio, Heerhugowaard, The Netherlands) and Upstate (Campro Scientific Veenendaal, The Netherlands), respectively. The tyrosine phosphatase (PTP) assay kits for detection of tyrosine phosphatase activity were purchased from Upstate. Phosphotyrosine clone PY-20 (610000) antibody was purchased from Becton-Dickinson (BD Bioscience, Alphen aan den Rijn, The Netherlands).

\section{Mice and preparation of BMMC}

BMMC were generated from bone marrow of male BALB/cBy and null $\mathrm{HSF}-1^{-/-}$mice (obtained from Dr. Ivor Benjamin, University of Texas Southwestern Medical Center) [20]. Briefly, mice were sacrificed, and intact femurs were removed. Sterile endotoxin-free RPMI medium was repeatedly flushed through the bone shaft using a syringe with a $25 \mathrm{G}$ needle. The suspension of bone marrow cells was centrifuged at $320 \mathrm{~g}$ for 10 minutes. After resuspending, cells were cultured at a concentration of $0.5 \times 10^{6}$ nucleated cells $/ \mathrm{mL}$ in $75-\mathrm{cm}^{2}$ flasks (Nunc) with $20 \mathrm{~mL}$ of complete medium, consisting of RPMI 1640 supplemented with $10 \%$ fetal calf serum (FCS; Sigma-Aldrich), 100 units $/ \mathrm{mL}$ of penicillin, $100 \mu \mathrm{g} / \mathrm{mL}$ of streptomycin (Life Technology, Breda, The Netherlands), $10 \mu \mathrm{g} / \mathrm{mL}$ of gentamycin, $2 \mathrm{mM}$ L-glutamine, $0.1 \mathrm{mM}$ nonessential amino acids, and a combination of IL-3 and SCF, at $37^{\circ} \mathrm{C}$ in a humidified atmosphere with $5 \% \mathrm{CO}_{2}$. Nonadherent cells were transferred to fresh medium at least once a week. After 3 to 4 weeks, when a mast cell purity of greater than $95 \%$ was achieved as assessed by toluidine blue staining, the cells were used for the experiments.

\section{BMMC treatments}

In all experiments, unless specified otherwise, cells were cultured at a density of $1 \times 10^{6}$ cells $/ \mathrm{mL}$ in $10-\mathrm{mL}$ tubes containing $2 \mathrm{~mL}$ of complete medium at $37^{\circ} \mathrm{C}$ in humidified atmosphere with $5 \% \mathrm{CO}_{2}$. Heat shock (HS) response was induced as described before [21]. Briefly, cells were incubated in an incubator at $43^{\circ} \mathrm{C}$ for 1 hour, using an incubator at $37^{\circ} \mathrm{C}$ as the control. After replacement of the culture medium with fresh medium, cells were further incubated for indicated periods of time, and then sensitized with $1 \mu \mathrm{g} / \mathrm{mL}$ of anti-DNP IgE from hybridoma clone 26.82 at $37^{\circ} \mathrm{C}$ for 1 hour. The cells were washed with medium and stimulated with 10 or $100 \mathrm{ng} / \mathrm{mL}$ of DNP-HSA at different time points for measurements as described below.

$L_{T} C_{4}$ and degranulation assays

For $\mathrm{LTC}_{4}$ measurements, BMMC were incubated with heat shock and sensitized with $1 \mu \mathrm{g} / \mathrm{mL}$ of anti-DNP IgE for 1 hour followed 
by stimulation with $10 \mathrm{ng} / \mathrm{mL}$ DNP-HSA. Sample supernatants were collected after 30 minutes and stored at $-70^{\circ} \mathrm{C}$ until analysis. $\mathrm{LTC}_{4}$ production was determined using an EIA kit according to the manufacturer's instructions.

To assay degranulation BMMC were pretreated with heat shock and sensitized with anti-DNP $\operatorname{IgE}$ at $37^{\circ} \mathrm{C}$ for 1 hour or 3 hours followed by stimulation with $10 \mathrm{ng} / \mathrm{mL}$ DNP-HSA. Then cells were washed twice with modified Tyrode's buffer supplemented with $0.1 \%$ bovine serum albumin (BSA) and $10 \mathrm{mM}$ HEPES, $\mathrm{pH} 7.2$, and resuspended in this supplemented buffer at a density of $0.6 \times$ $10^{6}$ cells $/ \mathrm{mL}$. Cells were aliquoted in 96 -well plates $\left(3 \times 10^{4}\right.$ cells per well) and activated with indicated concentrations of DNP-HSA for 30 minutes. Release of $\beta$-hexosaminidase was determined as described before [22].

\section{Intracellular calcium measurements}

Cells were incubated with heat shock as described before and then sensitized with $1 \mu \mathrm{g} / \mathrm{mL}$ of anti-DNP $\operatorname{IgE}$ at $37^{\circ} \mathrm{C}$ for 1 hour. Then, BMMC were washed with phosphate-buffered saline (PBS) containing $5 \%$ FCS and resuspended at a density of $5 \times 10^{6} / \mathrm{mL}$ in RPMI (without phenol-red) containing $0.5 \%$ BSA, $5.2 \mathrm{mM}$ Fura-Red AM, $2.1 \mathrm{mM}$ Fluo3 AM, and $2.5 \mathrm{mM}$ probenecid (SigmaAldrich), and incubated for 20 minutes at $37^{\circ} \mathrm{C}$. The cells were pelleted, resuspended in PBS containing 5\% FCS, and analyzed in a FACStar calibur flow cytometer (Becton-Dickinson, BD Bioscience) before (30 seconds) and after stimulation with $10 \mathrm{ng} / \mathrm{mL}$ DNP-HSA for 480 seconds [23]. The FACS profiles were converted to line graph data using the FCS Assistant version 1.3.1a application. Data were recorded as the relative ratio of fluorescence emitted at $526 \mathrm{~nm}$ and $670 \mathrm{~nm}$ after excitation at $488 \mathrm{~nm}$ and $635 \mathrm{~nm}$ (y-axis) over time (x-axis).

\section{Immunoprecipitation and immunoblotting}

Cells were incubated with heat shock as described before. Then cells were sensitized with anti-DNP IgE and activated with $10 \mathrm{ng}$ / $\mathrm{mL}$ or $100 \mathrm{ng} / \mathrm{mL}$ of DNP-HSA for 2 and 10 minutes. After 2 times washing in ice-cold PBS, cells were solubilized by lysis buffer (containing $50 \mathrm{mM}$ Tris, $\mathrm{pH}$ 8.0, $110 \mathrm{mM} \mathrm{NaCl}, 5 \mathrm{mM}$ EDTA, and $1 \%$ Triton $\mathrm{X}-100)$ and $1 \mathrm{mM}$ phenylmethylsulfonyl fluoride (PMSF), $100 \mu \mathrm{M} \mathrm{Na} \mathrm{VO}_{4}, 2 \mathrm{mM}$ para nitrophenyl phosphate (PNPP), and $210 \mathrm{mU} / \mathrm{mL}$ aprotinin. The resuspended pellet was incubated on ice for 30 minutes, followed by centrifugation at $8000 \mathrm{~g}$ for 10 minutes at $4^{\circ} \mathrm{C}$. The resulting supernatants were assayed for protein concentration by Bradford methods (Bio-rad Laboratories) and $500 \mu \mathrm{g}$ of each sample was subjected to immunoprecipitation and immunoblotting methods as described before [24].

\section{Total tyrosine phosphatase activity}

For determination of total tyrosine phosphatase activity, BMMC $\left(1 \times 10^{6}\right)$ were incubated with heat shock as described before. Then cells were sensitized with anti-DNP IgE and activated with $10 \mathrm{ng} / \mathrm{mL}$ DNP-HSA for 1,3 , or 5 hours at $37^{\circ} \mathrm{C}$. After that, cells were washed 2 times with cold saline, and after centrifugation were lysed with lysis buffer containing $50 \mathrm{mM}$ Tris, $110 \mathrm{mM} \mathrm{NaCl}$, 5 M EDTA, and 1\% Triton X100. Equal amounts of each lysate were subjected to the tyrosine phosphatase assay kit in accordance with the manufacturer's instructions as described before [25]. Briefly, $5 \mu \mathrm{g}$ of cellular protein was incubated with $4.5 \mu \mathrm{L}$ of substrate tyrosine phosphoprotein (amino acid sequence: RRLIEDAEpYAARG) and phosphatase assay buffer (20 mM MOPS, pH 7.5, $60 \mathrm{mM} \beta$-ME, $0.1 \mathrm{M} \mathrm{NaCl}$, and $0.1 \mathrm{mg} / \mathrm{mL}$ serum albumin) in total volume of $25 \mu \mathrm{L}$. Reactions were started with the addition of the respective phosphoprotein substrate and carried out for 10 minutes in room temperature. The reactions were terminated by the addition of $100 \mu \mathrm{L}$ of malachite green solution, and color was developed for 15 minutes before reading the plate at $650 \mathrm{~nm}$. All determinations were performed in duplicate, and the absorbances of the reactions were corrected by determining the absorbance from duplicate reactions not provided with the phosphoprotein substrate. The amount of phosphate released (pmoles) was then calculated from a standard curve (0-2000 pmoles).

Immunoprecipitation for SHP-1 and -2 was done as described previously [26] by first binding the PY-20 antibody to protein A-Sepharose beads (Santa Cruz Biotechnology) to which 50 million cell equivalents of total cell lysate were added. After incubation, the immune complex was washed and the associated proteins immunoblotted by anti-SHP-1 and anti-SHP-2 antibodies.

\section{Viability assay}

BMMC were treated with heat shock as described before, and incubated with fluorescein isothiocyanate (FITC)-labeled IgE $(386 \mu \mathrm{g} / \mathrm{mL})$ for 30 minutes. The supernatant was removed and cells were resuspended in PBS with $1 \%$ FCS and stained with annexin-V or 7-ADD (Becton-Dickinson; BD) by methods described in detail elsewhere [27]. Percentages of apoptotic and dead cells were assessed by flow cytometry using CellQuest software on a FACS Calibur flow cytometer (BD).

\section{Statistical analysis}

Differences in $\beta$-hexosaminidase activity, calcium, and leukotriene results between controls and the experimental groups were evaluated by one-way analysis of variance (ANOVA) and Student's $t$-test. $p<0.05$ was considered statistically significant.

\section{Results}

\section{Effects of heat shock on IgE/antigen}

induced leukotriene production and degranulation

In these experiments we determined the effect of heat shock on IgE-induced production of $\mathrm{LTC}_{4}$ and degranulation in wild-type and null $\mathrm{HSF}-1^{-/-}$mast cells. Activation with $\mathrm{IgE}$ and antigen caused rapid production of leukotrienes in BMMC from $\mathrm{HSF}_{-1}{ }^{+/+}$and $\mathrm{HSF}-1^{-/-}$animals (Fig. 1). Exposure to heat shock for 1 hour did not affect leukotriene production at 1 hour after heat shock treatment in either cell type (Fig. 1A and B).

Cross-linking of IgE with antigen induced degranulation in both $\mathrm{HSF}-1^{+/+}$and $\mathrm{HSF}-1^{-/-}$BMMC (Fig. 2). Heat shock inhibited the degranulation of BMMC in either cell type (Fig. 2A and B). Cell viability was not affected by heat shock $(95 \% \pm 2 \%$ vs $98 \% \pm 1 \%$ in control $)$.

\section{Heat shock suppresses calcium mobilization induced by cross linking of $\mathrm{IgE}$ and antigen}

The above-mentioned results indicated that induction of heat shock response by heat shock impairs the degranulation of mast cells independently of HSF-1. Because intracellular calcium has been shown to play a critical role in degranulation of mast cells [3], we studied intracellular calcium in the 
A

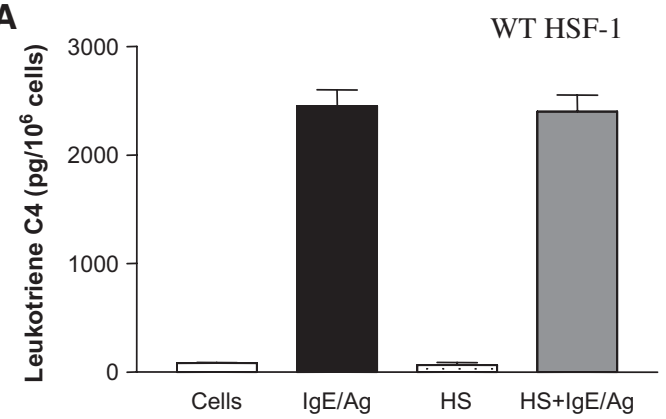

B

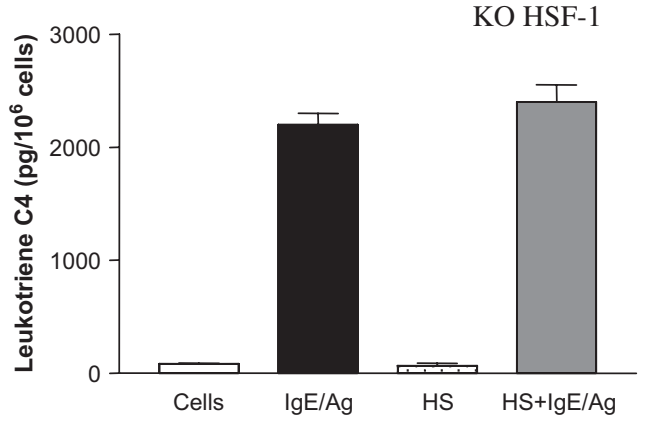

Figure 1. Heat shock does not affect leukotriene production of mast cells. BMMC (from BALB/cBy and HSF-1 ${ }^{-1-}$ null mice) were pretreated with heat shock, sensitized with DNP-specific IgE, and then stimulated with DNPHSA as described in Materials and methods. Production of leukotrienes illustrated in $\mathrm{HSF}_{-1}{ }^{+/+}$(A) and $\mathrm{HSF}_{-1}{ }^{-1-}$ (B) BMMC. Data represent means \pm SEM of quadruplicate samples.

presence of heat shock. As expected, sustained calcium rises were observed after activation of cells with ionomycine $(1 \mu \mathrm{M})$ and cross linking IgE with antigen (Fig. 3A and B). Exposure to heat shock significantly suppressed the calcium rise in cells activated by IgE cross linking but not in cells activated by ionomycin (Fig. 3A and B). Heat shock-induced inhibition of calcium was similar $(p=0.70)$ in HSF-1 ${ }^{-/-}$ cells (lower panel, Fig. 3B).

\section{Heat shock inhibits tyrosine}

phosphorylation of Syk and SHIP

To understand the mechanisms by which heat shock may influence calcium mobilization, we studied the effect of heat shock on tyrosine phosphorylation of Syk and SHIP enzymes. Activation of HSF-1 $1^{+/+}$BMMC by cross linking of IgE resulted in rapid tyrosine phosphorylation of Syk after 2 minutes and 10 minutes (Fig. 4, upper panel lanes 2 and 3 , respectively) compared to unstimulated cells (lane 1). Treatment of BMMC with heat shock prior to IgE cross linking resulted in greatly diminished phosphorylation of Syk after 2 and 10 minutes (Fig. 4, lanes 5 and 6, respectively). Heat shock itself did not induce Syk phosphorylation in unstimulated cells (lane 4). The same results were obtained in HSF-1 ${ }^{-1-}$ BMMC (Fig. 4, lower panel).

It has been reported that SHIP negatively regulates $\operatorname{IgE}$ receptor-induced activation of mast cells [28-30]. Increased activity of SHIP may contribute to the downregulation of
A
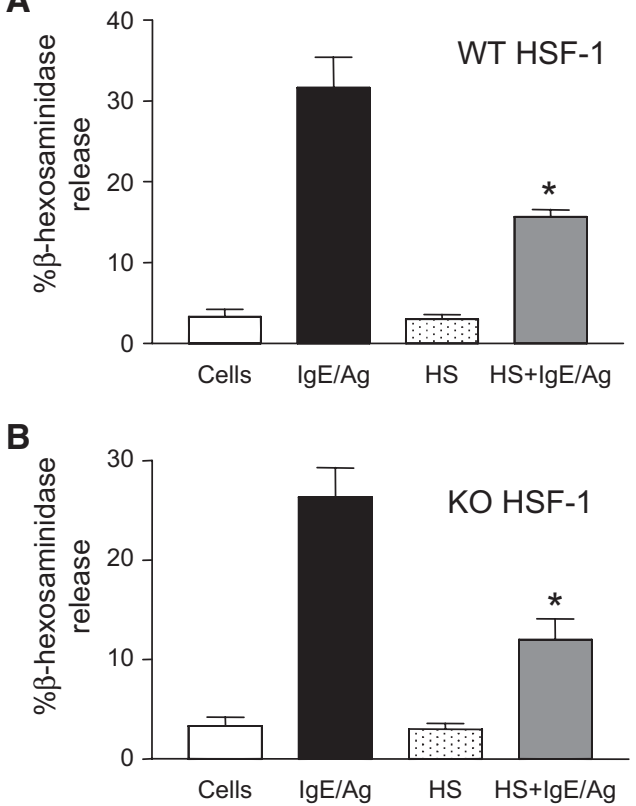

Figure 2. Heat shock suppresses degranulation of mast cells. BMMC (from $\mathrm{BALB} / \mathrm{cBy}$ and $\mathrm{HSF}-1^{-1-}$ null mice) were pretreated with heat shock, sensitized with DNP-specific IgE, and then stimulated with DNP-HSA and degranulation was measured as described in Materials and methods. Degranulation data illustrated in wild-type (A) and null HSF-1 ${ }^{-1-}$ (B) BMMC. Data are mean \pm SEM of quadruplicate samples. The asterisks represent significant differences compared with activated cells alone $\left({ }^{*} p<0.05\right)$.

mast cell activation caused by heat shock treatment. However, we did not find increased tyrosine phosphorylation of SHIP in activated mast cells that were heat shock treated. On the contrary, heat shock treatment caused a decrease in SHIP phosphorylation upon activation of cells (Fig. 5, upper panel, wild-type and lower panel, HSF-1 null-type BMMC).

\section{Heat shock increases tyrosine phosphatase activity}

Heat shock response leads to induction of phosphatase activity [31], which could be responsible for downregulation of cell activation. In BMMC cross linking of IgE induced an increase in the activity of tyrosine phosphatase (Fig. 6A). However, heat shock treatment alone induced a much greater increase in tyrosine phosphatase activity compared to $\operatorname{IgE}$ cross linking alone in wild-type (Fig. 6A, upper panel) and null HSF-1 BMMC (lower panel). The heat shockinduced activation of phosphatase activity was temporal, because at 3 hours after heat shock treatment phosphatase activity returned to basal levels (Fig. 7A). At this time point, also no inhibition of degranulation was observed anymore (Fig. 7B).

To further identify which tyrosine phosphatases may be affected by heat shock, we studied the activation of two tyrosine phosphatases, SHP-1 and SHP-2. Interestingly, heat shock increased the tyrosine phosphorylation of both SHP-1 and SHP-2 in wild-type (Fig. 6B) and null HSF-1 BMMC (data not shown). 

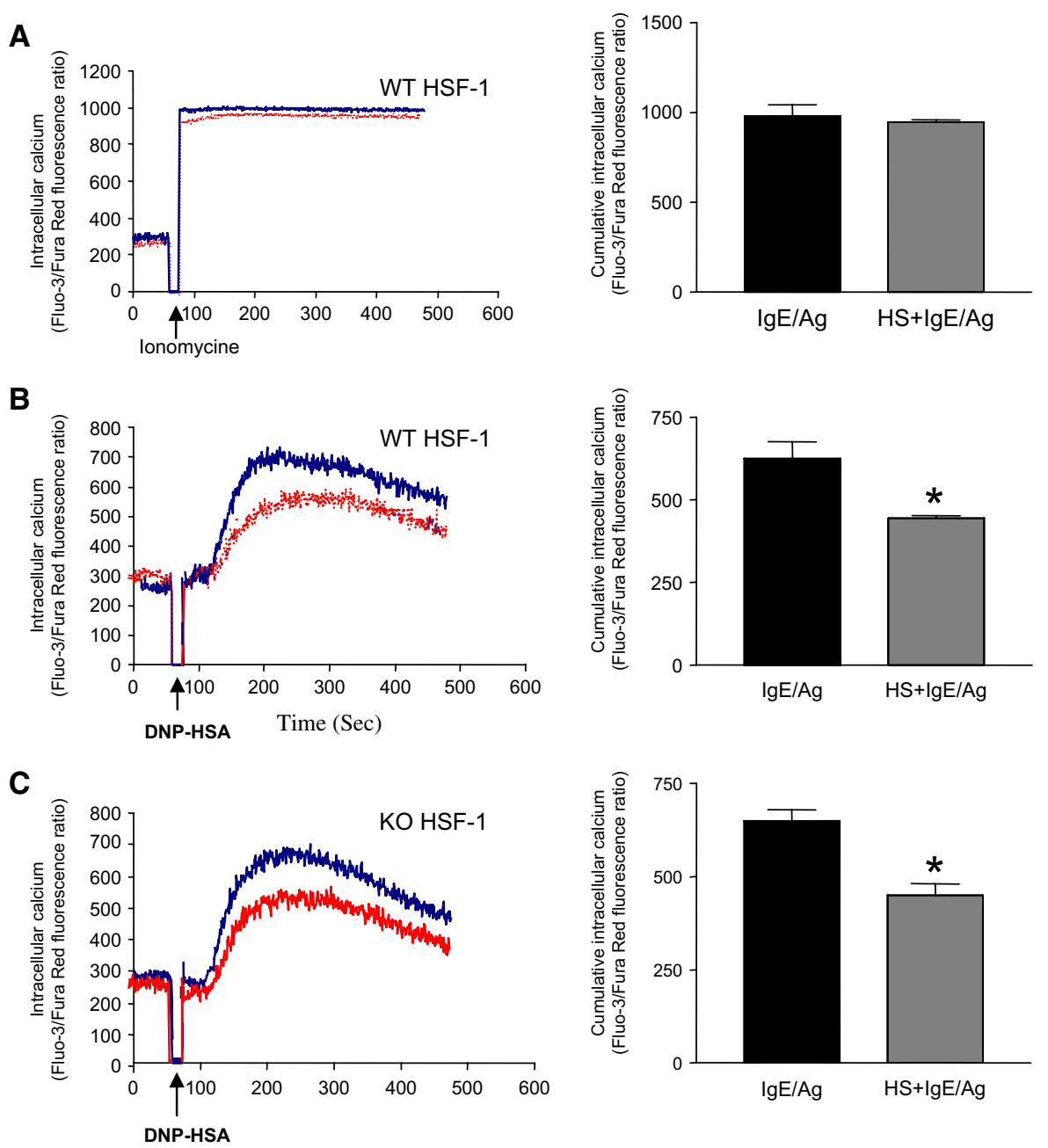

Figure 3. Heat shock suppresses calcium mobilization in activated mast cells. Control (black line) and heat shock-treated (grey line) BMMC were treated with heat shock for 1 hour and then recovered for 1 hour at $37^{\circ} \mathrm{C}$ and then prepared for $\left[\mathrm{Ca}^{2+}\right]_{\mathrm{i}}$ measurements as described in Materials and methods. Subsequently the cells were activated by $1 \mu \mathrm{M}$ of ionomycin (A) or at recovery time sensitized with DNP-specific IgE and then activated with $10 \mathrm{ng} / \mathrm{mL}$ DNP-HSA (B, upper and lower panels). Representative data from 3 separate experiments are shown (left panels). Cumulative Ca ${ }^{2+}$ mobilization $(30-$ $480 \mathrm{sec}$ ) is shown (results from 3 separate experiments) as mean \pm SEM $\left({ }^{*} p<0.05\right)$ (right panels). The asterisk represents a significant difference compared with activated cells alone $\left({ }^{*} p<0.05\right)$.

\section{Discussion}

In our present study, we show that mouse mast cells derived from a culture of bone marrow cells respond to heat shock by suppression of degranulation but not the production of leukotriene $\mathrm{C}_{4}$ upon activation with $\mathrm{IgE}$ and antigen. Previous data demonstrated differential regulation of the respective signal transduction pathways leading to exocytosis and lipid mediator production in mast cells $[32,33]$. Our present findings suggest that heat shock has differential and relatively specific effects on signaling pathways leading to mast cell activation and the release of mast cell mediators. Our results are in contrast with earlier findings in rat basophilic leukemia cells (RBL-2H3), in which heat shock did not affect degranulation [34]. The lack of response in these cells may be due to differences between tumor mast cell lines and primary cultured mast cells.
To identify the contribution of HSF-1 and HSP70 in the inhibitory effects on degranulation, we used BMMC from HSF- $1^{-I-}$ knockout mice. We showed earlier that in HSF$1^{-/-}$mast cells, heat shock did not induce expression of HSP70 (unpublished data, 2005). Surprisingly, in this study we found that heat shock was still able to inhibit degranulation, independently of HSF-1 and the expression of HSP70. From these data we can conclude that HSF-1 and HSP70 do not play a role in the heat shock-induced suppression of granule exocytosis by mast cells.

To address the mechanism of heat shock-induced suppression of degranulation in mast cells, we focused on the effect of heat shock on intracellular signaling pathways. Earlier studies revealed that stimulation of FceRI results in the rapid binding of the Syk tyrosine kinase to cytoplasmic domains of FceRI. Syk plays an essential role in signal 

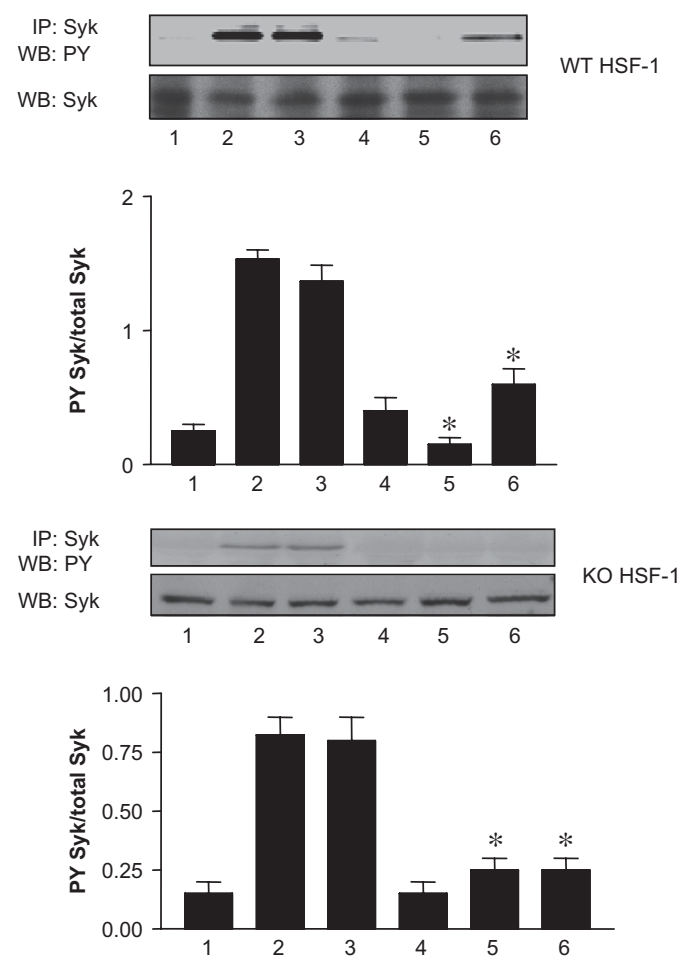

Figure 4. Heat shock inhibits tyrosine phosphorylation of Syk. BMMC (from BALB/cBy and $\mathrm{HSF}-1^{-/-}$null mice) were treated with heat shock and then stimulated with $\operatorname{IgE}$ and antigen as described in Materials and methods. Cells were lysed, and Syk was immunoprecipitated from the supernatants using Abs specific for Syk. Proteins were resolved by sodium dodecyl sulfate-polyacrylamide gel electrophoresis (SDS-PAGE) and analyzed by Western blot (WB) with anti-phosphotyrosine monoclonal antibody (mAb) PY-20 conjugated with horseradish peroxidase (HRP). After stripping, mAbs specific for Syk were used to estimate the relative amounts of the immunoprecipitated (IP) proteins. The data are representative of 3 separate experiments with similar results. The ratio of tyrosine-phosphorylated SyK to total Syk from 3 separate gels is shown in the lower panels. Data are mean \pm SEM of triplicate samples. The asterisks represent significant differences compared with activated cells alone $\left({ }^{*} p<0.05\right)$. Lane 1: untreated cells; lane 2: IgE/Ag-activated cells after 2 minutes; lane 3: $\operatorname{IgE} /$ Ag-activated cells after 10 minutes; lane 4: heat shock alone; lane 5: heat shock with IgE/Ag-activated cells after 2 minutes; lane 6: heat shock with $\mathrm{IgE} / \mathrm{Ag}$-activated cells after 10 minutes.

transduction from FceRI, as shown by Syk-deficient mast cells which are defective in receptor-induced degranulation, cytokine synthesis, and intracellular pathways $[35,36]$. Besides Syk, SHIP negatively regulates IgE receptor-induced degranulation as well as leukotriene and inflammatory cytokine production [30]. Moreover, SHIP has been shown to inhibit immune receptor activation in both mast cells and B lymphocytes by binding to the tyrosine-phosphorylated immunoreceptor tyrosine-based inhibition motif (ITIM) of the inhibitory coreceptor FcR $\gamma \mathrm{IIB}$ and inhibiting FceR1- and B-cell receptor-induced calcium influx, respectively [13]. In the present study we showed that heat shock dramatically reduced tyrosine phosphorylation of Syk and SHIP upon $\mathrm{IgE}$ and antigen stimulation. It has been shown that Syk phosphorylation coincides with increased enzymatic activity
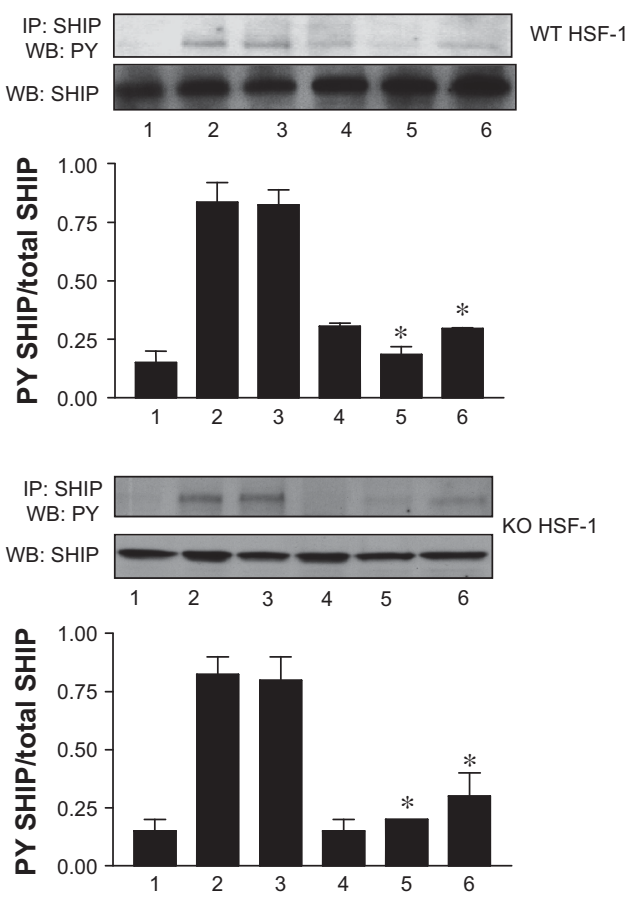

Figure 5. Heat shock inhibits tyrosine phosphorylation of SHIP. BMMC (from BALB/cBy and $\mathrm{HSF}-1^{-1-}$ null mice) were treated with heat shock and then stimulated with $\operatorname{IgE}$ and antigen as described in Materials and methods. Cells were lysed, and SHIP was immunoprecipitated from the supernatants using SHIP-specific Ab. Proteins were resolved by SDS-PAGE and analyzed by Western blot (WB) with anti-phosphotyrosine mAb PY20 conjugated with HRP. After stripping, mAbs specific for SHIP were used to estimate the relative amounts of the immunoprecipitated (IP) proteins. The data are representative of 3 separate experiments with similar results. The ratio of tyrosine-phosphorylated SHIP protein to total SHIP from 3 separate gels is shown in the lower panels. Data are mean \pm SEM of triplicate samples. The asterisks represent significant differences compared with activated cells alone $(* p<0.05)$. Lane 1: untreated cells; lane 2: IgE/Ag-activated cells after 2 minutes; lane 3: IgE/Ag-activated cells after 10 minutes; lane 4: heat shock alone; lane 5: heat shock with $\operatorname{IgE} /$ Ag-activated cells after 2 minutes; lane 6: heat shock with IgE/Ag-activated cells after 10 minutes.

$[7,8]$ Therefore, our results indicate that heat shock suppresses Syk activity.

It has been reported that SHIP is the primary enzyme responsible for breaking down phosphatidylinositol-3,4,5P3 (PIP3) in vivo in response to IgE-induced activation of PI-3 kinase [30]. The downregulation of degranulation by SHIP is probably not solely based on the breakdown of PIP3. It has been shown that activation of the IgE receptor results in binding of SHIP to the $\beta$ - and $\gamma$-chain of FCERI, which is followed by tyrosine phosphorylation on its NPXY domain $[12,30,37,38]$. Tyrosine-phosphorylated SHIP can then attract She via its PTB domain. She is probably phosphorylated by Syk and can then interact with SHIP's SH2-domain, wresting SHIP away from the membrane and thereby preventing PIP3 degradation. Furthermore, PKC- $\delta$ interacts with SHIP and Shc. PKC- $\delta$ was shown to be a negative regulator of mast cell degranulation. The net outcome of 

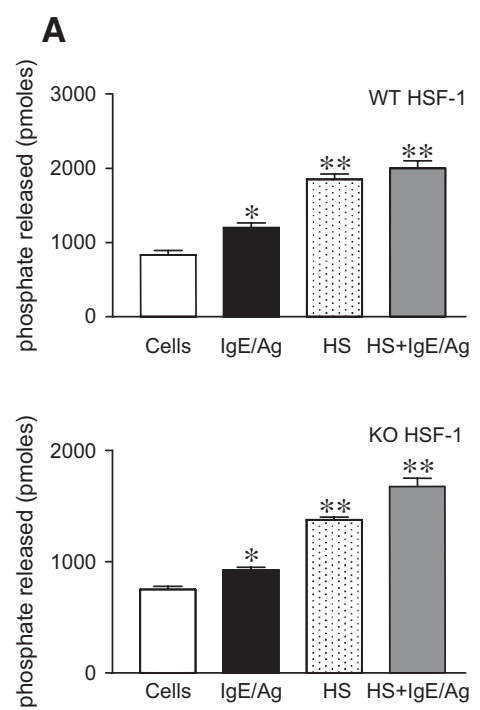

B
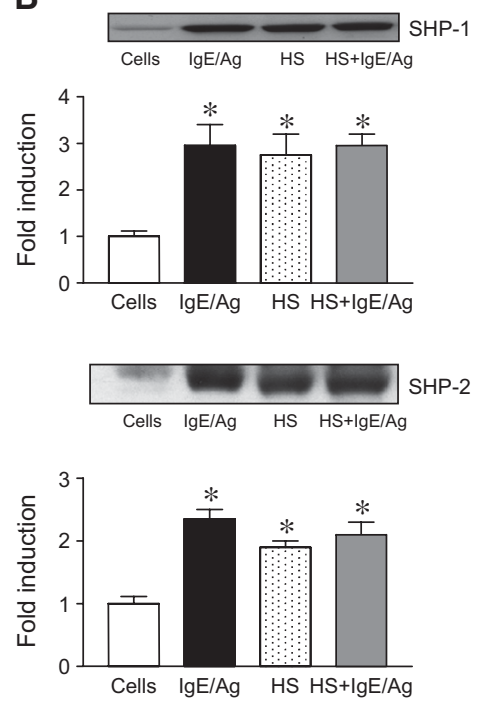

Figure 6. Heat shock increases tyrosine phosphatase activity in mast cells. (A): BMMC (from BALB/cBy and $\mathrm{HSF}-1^{-1-}$ null mice) were treated with heat shock and then stimulated with $\operatorname{IgE}$ and antigen after 1 hour as described in Materials and methods. Total phosphatase activity was determined in whole-cell lysates $(5 \mu \mathrm{g})$. Tyrosine phosphatase activity (measured by phosphate release) was present in unstimulated, control, and heat shock and IgE/Ag-treated cells in wild-type (upper panel) and HSF1-null BMMC (lower panel). Values are expressed as mean with $\mathrm{n}=10$ wells per condition. Graph represents data from 2 identically performed experiments. The asterisks represent significant differences compared with nonactivated cells $\left({ }^{*} p<0.05,{ }^{*} p<0.01\right)$. (B): Effects of heat shock and IgE and antigen on tyrosine phosphorylation of SHP-1 and SHP-2. BMMC were treated with heat shock for 1 hour. Cells were incubated with antiDNP IgE for 1 hour at $37^{\circ} \mathrm{C}$, stimulated for 10 minutes with DNP-HSA, and lysed. Whole-cell extracts were immunoprecipitated with phosphotyrosine antibody (PY-20) and then samples were immunoblotted with the indicated antibodies. In the lower panels data are expressed as fold induction of phosphorylation of SHP-1 and SHP-2. Results are displayed as mean \pm SEM of triplicate samples. The asterisks represent significant differences compared with cells alone $\left({ }^{*} p<0.05,{ }^{*} p<0.01\right)$.
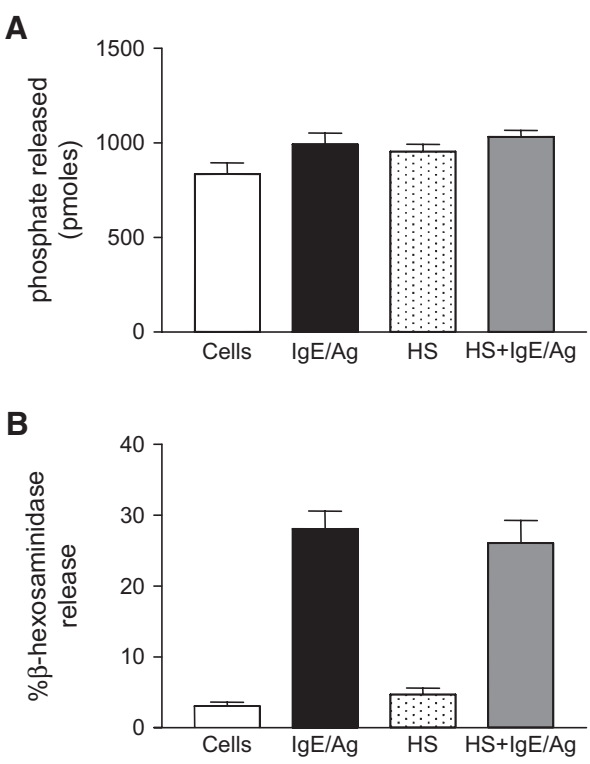

Figure 7. Heat shock does not affect tyrosine phosphatase activity and degranulation anymore after 3 hours. BMMC were treated with heat shock for 1 hour and then incubated at $37^{\circ} \mathrm{C}$ for 3 hours and then stimulated with IgE and antigen as described in Materials and methods. (A): Total phosphatase activity was determined in whole-cell lysates $(5 \mu \mathrm{g})$. Results are displayed as mean \pm SEM from 3 experiments performed in duplicate. (B): Degranulation was assessed by measuring the percentage of released $\beta$ hexosaminidase activity in supernatants. Data represent means \pm SEM of quadruplicate samples.

decreased phosphorylation of SHIP is difficult to predict. Decreased phosphorylation could have resulted in increased PIP3 breakdown, because less Shc can be recruited. However, we believe that the decreased phosphorylation might be due to a decreased phosphorylation of the IgE receptor and therefore reduced recruitment of SHIP to be phosphorylated in the vicinity of the receptor.

Because activation of Syk contributes to calcium influx in cells, which leads to the release of preformed mediators [5], we investigated whether heat shock modulates calcium mobilization upon IgE-receptor activation. Earlier reports showed that exogenous HSP70 induced increased calcium efflux [39] from neuronal cells. In our study, calcium mobilization triggered by FceRI aggregation was attenuated by heat shock, suggesting that suppression of degranulation may be related to the suppression of Syk activity and the reduction of the intracellular calcium influx. Because only a small increase in intracellular $\mathrm{Ca}^{2+}$ seems sufficient for activation of the lipoxygenase (5-LOX) pathway [40], the observed reduction of the calcium influx by heat shock is probably not sufficient to inhibit leukotriene production. Furthermore, there seems to be a good correlation between the increases in intracellular $\mathrm{Ca}^{2+}$ levels and the degree of degranulation. For example, Huber et al. [38] showed that the extent of degranulation of BMMC derived from $\mathrm{SHIP}^{+/+},{ }^{+/-}$, and ${ }^{-1-}$ animals increases nicely with increased $\mathrm{Ca}^{2+}$ mobilization. In our experiments, we have 
observed similar changes in $\mathrm{Ca}^{2+}$ levels and degranulation due to heat shock treatment. One major question that arises from our data is how heat shock, which does appear to inhibit calcium influx, affects Syk tyrosine kinase activity. Earlier studies have demonstrated that heat shock can lead to the induction of increased phosphatase activity [31,41], as well as phosphatase gene expression [25], and thereby shift the balance of phosphorylation and dephosphorylation.

Cross linking of IgE increased tyrosine phosphatase activity (Fig. 6A and B), and prior treatment of cells with heat shock further increased tyrosine phosphatase activity at 1 hour after heat shock exposure. Therefore, the increased activity of tyrosine phosphatase by heat shock may account for downregulation of tyrosine kinase activity leading to suppression of degranulation. The relation between tyrosine phosphatase activity and the attenuation of degranulation was further substantiated by the finding that 3 hours after heat shock exposure no increased phosphatase activity in mast cells was observed anymore and also no effect on degranulation was found. Furthermore we demonstrated that tyrosine phosphorylation of tyrosine phosphatase enzymes, i.e., SHP-1 and SHP-2, was increased by heat shock. It has been shown previously that tyrosine phosphorylation of SHP-1 increases its phosphatase activity [42,43]. Both enzymes can play a role in the suppression of mast cell activation, e.g., by dephosphorylating the $\beta$ or $\gamma$ subunits of the $\operatorname{IgE}$ receptor [44]. In conclusion, heat shock exposure of mast cells results in a temporal and differential inhibition of mast cell activation exemplified by a decreased degranulation and no effect on leukotriene synthesis. Our results indicate that heat shock induces a transient increase in tyrosine phosphatase activity shifting the balance of phosphorylation and dephosphorylation, resulting in a decrease in tyrosine phosphorylation of essential signaling molecules.

\section{References}

1. Galli SJ. New concepts about the mast cell. N Engl J Med. 1993; 328:257-265.

2. Beaven MA, Metzger H. Signal transduction by Fc receptors: the FceRI case. Immunol Today. 1993;14:222-226.

3. Kinet JP. The high-affinity IgE receptor (FceRI): from physiology to pathology. Annu Rev Immunol. 1999;17:931-972.

4. Turner H, Kinet JP. Signaling through the high-affinity IgE receptor FceRI. Nature. 1999;402:B24-B30.

5. Beaven MA, Rogers J, Moore JP, Hesketh TR, Smith GA, Metcalfe JC. The mechanism of the calcium signal and correlation with histamine release in 2H3 cells. J Biol Chem. 1984;259:7129-7136.

6. Burd PR, Rogers HW, Gordon JR, et al. Interleukin 3-dependent and -independent mast cells stimulated with $\mathrm{IgE}$ and antigen express multiple cytokines. J Exp Med. 1989;170:245-257.

7. Pribluda VS, Pribluda C, Metzger H. Transphosphorylation as the mechanism by which the high-affinity receptor for IgE is phosphorylated upon aggregation. Proc Natl Acad Sci U S A. 1994;91:1124611250.

8. Urtz N, Olivera A, Bofill-Cardona E, et al. Early activation of sphingosine kinase in mast cells and recruitment to FceRI are mediated by its interaction with Lyn kinase. Mol Cell Biol. 2004;24:8765-8777.
9. Yang J, Liang X, Niu T, Meng W, Zhao Z, Zhou GW. Crystal structure of the catalytic domain of protein-tyrosine phosphatase SHP-1. J Biol Chem. 1998;273:28199-28207.

10. Sozio MS, Mathis MA, Young JA, et al. PTPH1 is a predominant protein-tyrosine phosphatase capable of interacting with and dephosphorylating the $\mathrm{T}$ cell receptor $\zeta$ subunit. J Biol Chem. 2004;279: 7760-7769.

11. Binstadt BA, Billadeau DD, Jevremovic D, et al. SLP-76 is a direct substrate of SHP-1 recruited to killer cell inhibitory receptors. J Biol Chem. 1998;273:27518-27523.

12. Kalesnikoff J, Baur N, Leitges M, et al. SHIP negatively regulates IgE + antigen-induced IL- 6 production in mast cells by inhibiting NF$\kappa \mathrm{B}$ activity. J Immunol. 2002;168:4737-4746.

13. Ono M, Okada H, Bolland S, Yanagi S, Kurosaki T, Ravetch JV. Deletion of SHIP or SHP-1 reveals two distinct pathways for inhibitory signaling. Cell. 1997;90:293-301.

14. Wong HR. Potential protective role of the heat shock response in sepsis. New Horiz. 1998;6:194-200.

15. Christians ES, Yan LJ, Benjamin IJ. Heat shock factor 1 and heat shock proteins: Critical partners in protection against acute cell injury. Crit Care Med. 2002;30:S43-S50.

16. Morimoto RI, Kline MP, Bimston DN, Cotto JJ. The heat-shock response: regulation and function of heat-shock proteins and molecular chaperones. Essays Biochem. 1997;32:17-29.

17. Cahill CM, Waterman WR, Xie Y, Auron PE, Calderwood SK. Transcriptional repression of the prointerleukin $1 \beta$ gene by heat shock factor 1. J Biol Chem. 1996;271:24874-24879.

18. Feinstein DL, Galea E, Aquino DA, Li GC, Xu H, Reis DJ. Heat shock protein 70 suppresses astroglial-inducible nitric-oxide synthase expression by decreasing NFKB activation. J Biol Chem. 1996;271: 17724-17732.

19. Galli SJ, Lantz CS. Allergy. In: Paul WE, ed. Fundamental Immunology. Philadelphia: Lippincott-Raven; 1999. p. 1127-1174.

20. Xiao X, Zuo X, Davis AA, et al. HSF1 is required for extra-embryonic development, postnatal growth and protection during inflammatory responses in mice. EMBO J. 1999;18:5943-5952.

21. Wong HR, Ryan M, Wispe JR. Stress response decreases NF- $\kappa B$ nuclear translocation and increases $\mathrm{I}-\kappa \mathrm{B} \alpha$ expression in A549 cells. J Clin Invest. 1997;99:2423-2428.

22. Karimi K, Redegeld FA, Blom R, Nijkamp FP. Stem cell factor and interleukin-4 increase responsiveness of mast cells to substance P. Exp Hematol. 1999;28:626-634.

23. Lee RJ, Oliver JM. Roles for $\mathrm{Ca}_{2}{ }^{+}$stores release and two $\mathrm{Ca} 2^{+}$influx pathways in the FceR1-activated $\mathrm{Ca}^{+}{ }^{+}$responses of $\mathrm{RBL}-2 \mathrm{H} 3$ mast cells. Mol Biol Cell. 1995;6:825-839.

24. Furumoto Y, Nunomura S, Terada T, Rivera J, Ra C. The FceRI $\beta$ immunoreceptor tyrosine-based activation motif exerts inhibitory control on MAPK and IKB kinase phosphorylation and mast cell cytokine production. J Biol Chem. 2004;279:49177-49187.

25. Sanlorenzo L, Zhao B, Spight D, et al. Heat shock inhibition of lipopolysaccharide-mediated tumor necrosis factor expression is associated with nuclear induction of MKP-1 and inhibition of mitogen-activated protein kinase activation. Crit Care Med. 2004;32:2284-2292.

26. Swieter M, Berenstein EH, Swaim WD, Siraganian RP. Aggregation of ige receptors in rat basophilic leukemia $2 \mathrm{H} 3$ cells induces tyrosine phosphorylation of the cytosolic protein-tyrosine phosphatase HePTP. J Biol Chem. 1995;270:21902-21906.

27. Schmid I, Uittenbogaart CH, Giorgi JV. Sensitive method for measuring apoptosis and cell surface phenotype in human thymocytes by flow cytometry. Cytometry. 1994;15:12-20.

28. Kalesnikoff J, Lam V, Krystal G. SHIP represses mast cell activation and reveals that IgE alone triggers signaling pathways which enhance normal mast cell survival. Mol Immunol. 2002;38:1201-1206.

29. Xu R, Abramson J, Fridkin M, Pecht I. SH2 domain-containing inositol polyphosphate $5^{\prime}$-phosphatase is the main mediator of the inhibitory 
action of the mast cell function-associated antigen. J Immunol. 2001; 167:6394-6402.

30. Huber M, Kalesnikoff J, Reth M, Krystal G. The role of SHIP in mast cell degranulation and IgE-induced mast cell survival. Immunol Lett. 2002;82:17-21.

31. Keyse SM, Emslie EA. Oxidative stress and heat shock induce a human gene encoding a protein-tyrosine phosphatase. Nature. 1992;359: 644-647.

32. Ferry X, Eichwald V, Daeffler L, Landry Y. Activation of B $\gamma$ subunits of Gi2 and Gi3 proteins by basic secretagogues induces exocytosis through phospholipase $\mathrm{CB}$ and arachidonate release through phospholipase $\mathrm{C} \gamma$ in mast cells. J Immunol. 2001;167:4805-4813.

33. Shefler I, Taube Z, Medalia O, Sagi-Eisenberg R. Basic secretagogues activate protein tyrosine phosphorylation and release of arachidonic acid in mast cells via a novel protein kinase $\mathrm{C}$ and phosphatidylinositol 3kinase-dependent mechanism. Eur J Immunol. 1998;28:3468-3478.

34. Bachelet M, Marchand F, Souil E, et al. Expression and localization of heat shock proteins in rat basophilic leukemia cells: differential modulation by degranulation, thermal or oxidative stress. Allergy. 2002;57:791-797.

35. Siraganian RP, Zhang J, Suzuki K, Sada K. Protein tyrosine kinase Syk in mast cell signaling. Mol Immunol. 2002;38:1229-1233.

36. Costello PS, Turner M, Walters AE, et al. Critical role for the tyrosine kinase Syk in signaling through the high affinity $\operatorname{IgE}$ receptor of mast cells. Oncogene. 1996;13:2595-2605.

37. Huber M, Helgason CD, Damen JE, Liu L, Humphries RK, Krystal G. The src homology 2-containing inositol phosphatase (SHIP) is the gatekeeper of mast cell degranulation. Proc Natl Acad Sci U S A. 1998;95:11330-11335.

38. Huber M, Helgason CD, Scheid MP, Duronio V, Humphries RK, Krystal G. Targeted disruption of SHIP leads to Steel factor-induced degranulation of mast cells. EMBO J. 1998;17:7311-7319.

39. Smith PJS, Hammar K, Tytell M. Effects of exogenous heat shock protein (hsp70) on neuronal calcium flux. Biol Bull. 1995;189:209-210.

40. Malaviya R, Malaviya R, Jakschik BA. Reversible translocation of 5lipoxygenase in mast cells upon IgE/antigen stimulation. J Biol Chem. 1993;268:4939-4944.

41. Grossman BJ, Shanley TP, Denenberg AG, Zhao B, Wong HR. Phosphatase inhibition leads to activation of IкB kinase in murine macrophages. Biochem Biophys Res Commun. 2002;297:1264-1269.

42. Uchida T, Matozaki T, Noguchi T, et al. Insulin stimulates the phosphorylation of Tyr538 and the catalytic activity of PTP1C, a protein tyrosine phosphatase with Src homology-2 domains. J Biol Chem. 1994;269: 12220-12228.

43. Li RY, Gaits F, Ragab A, Ragab-Thomas JM, Chap H. Tyrosine phosphorylation of an $\mathrm{SH} 2$-containing protein tyrosine phosphatase is coupled to platelet thrombin receptor via a pertussis toxin-sensitive heterotrimeric G-protein. EMBO J. 1995;14:2519-2526.

44. Kimura T, Zhang J, Sagawa K, Sakaguchi K, Appella E, Siraganian RP. Syk-independent tyrosine phosphorylation and association of the protein tyrosine phosphatases SHP-1 and SHP-2 with the high affinity IgE receptor. J Immunol. 1997;159:4426-4434. 